\title{
Ecological Education as a Factor of Mining Engineer Training
}

\author{
Elena Sigareva ${ }^{1, *}$, Gennady Devyatkin ${ }^{1}$, and Sergey Baturin ${ }^{1}$ \\ ${ }^{1}$ Kemerovo institute (branch) of Plekhanov Russian University of Economics, Department of \\ humanities, 650992 Kuznetsky pr. 39, Kemerovo, Russia
}

\begin{abstract}
To reduce environmental tension the development of Kuzbass ecological culture is of great importance. Its most significant component is environmental education, in general, and the training of mining engineers with high level of ecological education, in particular. The presence of environmental education in the field of nature management cannot yet become a guarantor of environmental problems solution. It should be embodied in the behavior of a person, in the image of his life, in the system of values, in his ecological worldview. Educational reforms have become a response to the challenges posed by the social-and-economic development to the personality of a specialist, including the personality of a mining engineer in Russia and its regions. To identify the features of environmental education in the transition to the sustainable development it is important to set the main links in the system of continuous education and their peculiarities, which radically change the quality of training of mining engineers and the demand for specialists in the labor market.
\end{abstract}

\section{Introduction}

Kuzbass is a region which industrial development and population density determined the situation in the West Siberian Federal District as the leading one by these indicators. On the other hand, anthropogenic impact on the environment has led to the pollution of water, air and soil, exceeding the maximum permissible concentration of harmful substances. Currently, the urgent environmental problems are correlated with the low level of education in the country. An important role in the development of environmental education is carried out by continuous education, widely disseminated in scientific and practical activities at the end of the last century in Russia. The goal of continuous education is the spiritual development of the personality not only from the position of aesthetic and moral development, but in the aggregate of the rational, conscious in a person in conjunction with the ethical norms and requirements of society. The problem of the development of an environmentally oriented personality continues to remain relevant at the present stage.

In modern conditions, there is a development of a multi-level continuous environmental education, consisting of the following:

- ecological education and education of preschool and school children;

- secondary vocational education;

\footnotetext{
* Corresponding author: sigareva@mail.ru
} 
- higher education;

- expert activity.

The restructuring aim of mining education, taking into account the ecological aspect, is to implement new directions for improving the quality and scientific level of education, teaching technologies for solving long-term objectives of nature management based on the integration of university and academic science, ensuring effective satisfaction of demand in the labor market and the rational use of natural resources.

\section{Material and Methods}

The generalized experience of training personnel at all levels in the field of environmental management shows that the very existence of environmental education in the field of nature use, which is systemic, continuous and justified, is not yet a guarantor of environmental problems solution in environmental management. It must be embodied in human behavior, in the image of his life, in the system of values, in his ecological worldview. The connection of environmental education with the economy, politics, social development, human life determines setting the goal. The goal of environmental education was not only the development of the ecological culture of future mining engineers through education, training, education at the level of theoretical (abstract) development, but experimental and practical activities aimed at reducing the anthropogenic factor in specific conditions (not so much in the country or region, as in a certain settlement, mono-city, etc.).

Training of mining engineers is complicated by a number of problematic issues affecting educational and social aspects. They relate to the unavailability of specialists in production. Today, we need specialists who know not only the technological problems of mining, but also their consequences, that is, new approaches in the training of personnel are needed.

The first major step towards the development of the proposed concept of environmental education was made in 2010, when the interuniversity student group, which included students from different universities and different courses and specialties, developed a social and economic project for the settlement of the Kemerovo region. This project was developed by order of the Kemerovo region authorities. Working on the project, students used knowledge about integrated nature management, environmentally friendly technologies, and methods of resource and energy conservation [1-3].

An original idea for the development of Russian village was proposed. This project was a complex of ecologically modern measures that allow increasing the economic and social components of the development of Ust-Chebula village in the Kemerovo region. The project was highly appreciated at the regional contest of municipal development projects in the Kemerovo region and was recommended for the implementation by SDS "Agro".

In March, 2013 a student environmental team "KemEkolOS" was set up on the basis of KuzSTU. The team members extensively participate in environmental events. The students of KuzSTU participate in scientific research, in the development of environmental projects and environmental protection technologies.

The most important task for modern Russian economy is to improve the life quality of Russian citizens. The life quality as a multi aspect social phenomenon is determined by the historically determined type of living that makes up the society groups and is formed under the influence of a number of factors. Environmental education plays an important role in the development of a new image of the Kemerovo region upon which the life quality of its population largely depends.

For the first time the theory of life quality as an ecological determinant was studied by the representative of the geographical school of social philosophy, Sh. L. Montesquieu. In his work "About the spirit of laws" he revealed the relationship between climatic and natural 
conditions, on the one hand, and the type of activity, health, ethic and morality on the other. $[4,5]$.

The analysis of the life quality concept leads to the consideration it as an integrated system that reflects the impact of social-and-demographic indicators, indicators of social tension, the level of material well-being and the level of goods and services consumption, as well as the environmental component as a whole. The life quality of the population is formed, in addition, under the influence of regional factors (specialization of the region, the local taxes amount and so on). Except the certain parameters, a number of researchers in the ecological aspect of life quality philosophy also emphasize the "restoration of the normal physical life environment of a person".

The category of life quality is being investigated on a global scale; the main parameter of this approach is population growth. In modern economic science, in connection with population growth, a new trend has been developed - ecological neo-Malthusianism. The founders of this school consider "demographic trends as independent variables in the system of public relations". According to P. Ehrlich, the German scientist and Nobel Prize winner, the "explosion of the human population" represents a very significant factor in the degradation of nature, increasing consumption, which in turn leads to a decrease in living standards". At the same time, as an essential measure of population growth regulation, an artificial reduction in the birth rate is proposed on a national scale [6-8].

The growth of the global population takes place mainly due to the developing countries, which affects the global natural resources, the degree of their usage, and consequently, the quantitative and qualitative depletion and pollution of the environment by industrial, agricultural and municipal waste - all this worsens the environmental situation at the global level. Thus, in our opinion, there is a "collision" between two aspects of the life quality theory: social-and-economic, the main parameter of which is the enrichment by material goods and the increase in their consumption level, and the social-and-ecological one - to achieve the high level of favorable environment - the life in harmony with nature. In this context, a link with industrial entrepreneurial activity is being formed with the help of "ecological culture" concept. Environmental culture is a way of human development in harmony with the surrounding natural environment.

Some researchers propose to determine the life quality, emphasizing "its relationship with the quality of the environment and the requirement for humanizing an individual in society" [9-10]. In this context, a person must be given freedom and creativity, without violating his physical and mental values, based on a "tolerant social environment" [11-12].

Using the theoretical preconditions for the interaction between ecology and the life quality, we made a retrospective analysis of the environment by the Kemerovo region example.

On the territory of the Kemerovo region there are environmentally protected sites, including those of federal importance, where nature remains untouched. They are the Kuznetsky Alatau State Nature Reserve, the Shorsky National Park and the Lipovy Ostrov nature monument, the regional open-air museum "Tomskaya Pisanitsa", the Kuzbass Botanical Garden, the zones of mass recreation, sports and tourism, state nature reserves, green zones of cities, areas of settlements with natural healing factors (Borisovo, Tersinka), the zone with historical and cultural monuments. Their total area is $15 \%$ of the entire territory of Kuzbass, which is one of the highest in Siberia. The reserve "Kuznetsky Alatau" is notable for its uniqueness, its flora and fauna are of a mixed nature, biological diversity is observed. Shorsky National Park is one of the largest national parks in Russia and the only national park on the territory of Western Siberia.

The deposits of iron ore, manganese, gold, silver, zinc, copper and other minerals are being actively mined in Kuzbass. The territory of the Kemerovo region is located in the southeastern part of Western Siberian lowland in the Kuznetsk coal basin, which gave the 
second official name to the region - Kuzbass. This area is one of the world's most unique coal deposits. Almost all existing types of coal are represented here. The peculiarities of the climate and geographic location of the Kemerovo region contribute to the fact that most of the industrial emissions of pollutants are not dispersed in the atmospheric air, but precipitated in the Kuznetsk Basin, and a photochemical smog is being formed. This has a negative impact on the health of the population. The air quality in the Kemerovo region is influenced by various factors, first of all, the economic type of the region, an industrial, as well as the degree of industrialization, the presence of highways networks with intensive traffic, and geographical location and climatic features.

The essential pollutants of Kuzbass rivers are oil products, phenols, compounds of nitrogen, iron, copper, zinc, manganese. The Basin of Tom River, the main waterway of the region, is polluted with sewage from mining, fuel and energy, metallurgy, coke chemical, chemical, woodworking industries, agro-industrial complexes and municipal services.

Existing wildlife management areas and monuments are a serious aspect increasing the social-and-ecological and cultural components of the life quality of a person. Of no less importance is the development of snow tourism in the territory of the Kemerovo region, which is probably a prerequisite for the creation of a special natural zone of a touristrecreational type on the basis of existing parks and reserves. The huge natural potential of Kuzbass should become the basis for "building a new image" - agro-industrial and tourist, according to the opinion of employees group from the Kuzbass State Technical University. In general, it should contribute to improving the life quality of the population of Kuzbass.

Thus, industrial enterprises damage the environment, which ultimately has an adverse effect on human health. In this regard, the problem of the life quality largely depends on the competence of the specialist, the ability to foresee not only the immediate but also remote consequences of the coal mining industry influence on the population life quality, the state of its health, life expectancy. Obviously, the development of a new image of the Kemerovo region is becoming an important stage in the training of ecological culture of mining engineer, as well as the way of his life as a specialist.

\section{Results and Discussion}

As a result of a retrospective analysis of environmental education during the training process of mining engineers at the Kuzbass State Technical University, the features and goal of environmental education have been revealed.

Ecological education at T.F. Gorbachev Kuzbass State Technical University is an open system. Its structure includes constituent elements such as a municipal educational institution - a gymnasium, a research and educational center for pre-engineering training, secondary vocational education (SVE) on the basis of a technical university schoolchildren of 9, 11 grades are trained by the following specialties: "Open mining works", "Underground mining of mineral deposits", etc. The Pre-Engineering Training Center of KuzSTU admits students of 5-10 grades from general education schools which are given advanced training in areas: earth science, robotics, artificial intelligence, intelligent electrical engineering and other fields of engineering and technical creativity. The aim of the Center is to identify gifted children for further study at the university.

Environmental education at KuzSTU is carried out as an autonomous, having its own specificity. Its main feature is the external factor: the university's cooperation with federal and regional authorities, the Administration of the Region and the City Administration, the Kuzbass Technopark, industrial enterprises and companies. Most management and engineering staff members in Kuzbass main industries are KuzSTU graduates.

The concept of environmental safety of nature management is considered to be of great importance. The term nature management refers to the totality of all forms of exploitation of 
the natural resource potential and measures for its conservation and reproduction. First of all, these are the conditions necessary for the existence of society that is extraction and processing of natural resources, their protection, renewal and reproduction. An important role is played by specific forms of life activity associated with the use and protection of the natural environment of human habitat; the development of a society based on preservation, reproduction and rational change of ecological balance of natural systems.

Environmental education in technical universities, in particular at KuzSTU, consists mainly of disciplines that teach the general ecology, industrial ecology, social ecology. The university trains the greatest number of future users of natural resources, mining engineers, in the following specialties: mining, surveying, electricity, mining machines and equipment, mine and underground construction, chemical technology of inorganic substances, chemical technology of organic substances, chemical technology of energy carriers and carbon materials , cars and automobile facilities and others. Since 2012, the training period of mining engineers at KuzSTU has been five and a half years.

The main tasks which are set today before environmental education are the following:

1. To develop the idea that a person is a part of nature, that there is a unity of all living creatures and the impossibility of human survival in the conditions of a global ecological crisis.

2. To teach future mining engineers to develop measures for reducing anthropogenic impact on the environment within a populated area, an enterprise, a district or a region.

3. To acquaint the students with the analytical methods of ecological studies, to teach to apply them in the scientific projects.

4. To involve in the development of eco-protective technologies, environmental actions, creative events, academic competitions.

5. To promote the expansion of scientific interests of students, to stimulate constant improving the level of knowledge in the environmental and professional fields.

When studying the disciplines "Ecology", "Environmental Monitoring", "Environmental Safety", etc. innovative educational technologies and methods are used, such as audiovisual training, i.e. training with the help of technical means, lecture-conferences, role-plays, innovative forms of tests, research methods, application of electronic educational resources, work in groups, case-studies. Interactive electronic publications are developed and applied in educational process of these disciplines.

As part of the development of environmental education system at the university, students are expected to participate in environmental events and competitions, in the development of innovative technologies for environmental protection, participation in grant programs for research funding, scientific conferences, academic competitions on environmental problems. They apply their knowledge obtained in the process of study in practical activities, expand the scientific interests, and constantly increase the level of knowledge in the environmental and professional fields. Only in this case it is possible to form an ecological outlook for young people based on their own experience and theoretical knowledge.

\section{Conclusion}

Thus, the system of environmental education of mining engineers is a complex multi-level structure; the interaction of all its elements is the basis for effective training of future specialists. Identified features of environmental education cannot ignore the action of any one element of this structure. New approaches in environmental education of mining engineers influence the formation of a new image of the Kemerovo region; contribute to the process of successful development of environmental culture of the population in the region, and the life quality. 


\section{References}

1. F. Alt, Das ökologische Wirtschaftswunder (Wissenschaft, Berlin, 2001)

2. A. Balabanova, V. Balabanov, E. Dotsenko, N. Ezdina, E3S Web of Conf., 15, 04013 (2017)

3. D. Brock-Unte, Educating for peace: a feminist perspective (Springer, New York, 1985)

4. I. J. Gibul, Ecological needs: essence, dynamics, prospects (Bela, Minsk, 1991)

5. V. Zolotukhin, N. Zolotukhina, M Yazevich, A. Rodionov M. Kozyreva, E3S Web of Conf., 21, 04008 (2017)

6. E. Makarevich, A. Papin, A. Nevedrov, T. Cherkasova, A. Ignatova, E3S Web of Conf., 21, 02005 (2017)

7. T. Maltus, Experience on the law of population (AVSD, Petropavlovsk, 199)

8. C. Merchant, Death of nature: women, ecology and scientific revolution (HTUV, SanFrancisco, 1980)

9. N. F. Reimers, Nature management (Nauka, Moskow, 1990)

10. E. Sigareva, S. Popov, S. Baturin, N. Sidorova, M. Borisova, E3S Web of Conf., 15, 04009 (2017)

11. B. Torak, The green alternative: Creating an ecological future (Sun, San-Pedro, 1987)

12. P. R. Ehrlich, The Population Bomb (Ballantine Books, NY, 1968) 